\title{
Should Physicians Elicit Parental Permission before Providing Termination of Pregnancy to All Adolescent Patients?
}

\author{
Željka Stamenkovići , Vida Jeremić Stojković ${ }^{2}$ \\ ${ }^{1}$ Institute of Social Medicine, Faculty of Medicine, University of Belgrade, Belgrade, Serbia, ${ }^{2}$ Department of Humanities, \\ Faculty of Medicine, University of Belgrade, Belgrade, Serbia
}

Correspondence: zeljka.stamenkovic@med.bg.ac.rs; Tel. / Fax.: + 381112643830

Received: February 26, 2021; Accepted: June 1, 2021

\begin{abstract}
We aimed to present a review of current legal regulations worldwide and the main arguments for and against the requirement of parental consent for abortion in adolescents. While confidentiality in sexual and reproductive healthcare has been guaranteed to adolescents in many countries, many physicians disagree with the practice of providing confidential abortion to adolescents without parental consent. The main reason is that adolescents are not sufficiently mature and competent to independently make decisions and that they need parental protection. Adolescents who are willing to involve parents in their abortion decision will likely benefit from the adult experience and support. The existence of parental involvement legislation reduces the number of adolescent's abortions. There is a consensus that adolescents should have access to confidential health services and that parental involvement, should not be a barrier to care. However, the majority of adolescents aged 14 to 17 are as competent as adults to understand the risks and benefits of abortion, make voluntary decision ns and provide consent without parents. Also, mandatory parental notification on the intent to undergo abortion may be a trigger for family violence which is dangerous for adolescents and may have long-term consequences. Conclusion - We support the thesis that involving parents in the process of pregnancy termination should not be mandatory. It should be the decision of a competent adolescent and the obligation rests on the medical professionals to assess the ability of the adolescent to make a competent decision about abortion.
\end{abstract}

Key Words: Parental Permission • Adolescents • Minors • Pregnancy • Abortion.

\section{Introduction}

Pregnancy and induced abortion in adolescence have been considered as both public health and bioethical issue. Pregnancy in adolescence often represents a threat to adolescent mother's health. In fact, pregnancy and delivery are the leading global causes of mortality in the population of adolescents aged 15-19 years due to increased risk of eclampsia, puerperal endometritis and sepsis $(1,2)$. Moreover, it is estimated that 3.9 million unsafe abortions have been performed annually at a global level in girls aged 15-19 years, which also contributes to the morbidity and mortality in this population (3). Although confidentiality in sexual and reproductive health care has been guaranteed to adolescents in many countries, many physicians disagree with the practice of providing confidential abortion to adolescents without parental consent $(4,5)$. The main reason behind this position is that adolescents are not sufficiently mature and competent to independently make adequate decisions and that they need parental protection. The decision to have an abortion is not easy even for adults.

Abortion is a procedure that has its risks and also could have long-term consequences on physical, mental and social health. For identifying and reviewing studies that explored different aspects of parental involvement or parental permission to terminate adolescent pregnancy, and for identify- 
ing and reviewing relevant national and international literature on this topic, a systematic literature search strategy was performed. Studies published in scientific literature included in two academic databases PubMed and Google Scholar were evaluated. No limitations in terms of study design were applied. Only human and studies in the English language were included. To find the articles of interest we performed a more detailed PubMed search strategy using free text words (ie. non-MeSH terms). For identifying relevant and international literature related to parental involvement or parental permission to terminate adolescent pregnancy, a literature search in Google Scholar in the English language was performed.

This paper presents a review of current legal regulations worldwide and main arguments for and against the requirement of parental consent for abortion in adolescent patients.

\section{Current Legal State of Affairs in the Industrialized Countries}

In the US, thirty-seven states currently require some kind of parental involvement for minors seeking abortions (6). Thus far, in thirteen states (Alaska, Connecticut, District of Columbia, Hawaii, Maine, Nevada, New Jersey, New Mexico, Montana, New York, Oregon, Vermont and Washington) a minor may consent to an abortion without parental consent (7). In Europe, almost all countries have regulations on requiring parental permission/consent for adolescents who are seeking abortion with variations in the age limit when parents must be informed (8). In the Netherlands, for example, an adolescent aged between 12 and 16 years needs to provide parental consent. But, under special circumstances, a girl should contact her general practitioner or a doctor at an abortion clinic who will decide whether she fully understands the consequences of her decision to undergo an abortion. The duty of a doctor is to provide confidentiality of their patient which means that he/she will not inform the parents about abortion unless the girl agrees. Also, if a girl is aged between 16 and 18 years, she only needs parents' consent if the doctor decides that she is unable to make an autonomous decision on her own. Also, girls under the age of 12 need parental consent for an abortion (9). In Switzerland, Norway and Serbia, parental consent is required if a girl is under 16 years of age (10-12). In Switzerland, for example, adolescents under the age of 16 must see a counsellor at a counselling service for adolescents, but parental consent is not required for adolescents capable of discernment (even if they are under 16) (10). In Austria, the law stipulates that if a girl is aged between 14 and 18, she can consent to medical treatment only if she can understand the procedure and make a decision. If the adolescent lacks the ability to understand and decide on a treatment, the approval of a parent or legal guardian is required (12). In Greece, Italy and Germany, girls under the age of 18 must get written permission from a parent or guardian before being allowed an abortion. However, in Germany should an adolescent wish to keep her pregnancy confidential, the doctor can decide if she is mature enough to make that choice herself or whether the parents should be informed and make the decision for her (12). In the UK, competent adolescents regardless of age can independently consent to any medical treatment, including termination of pregnancy. Only if an adolescent patient is determined to lack competence, a parent or guardian may consent to termination on her behalf (13). The situation is similar in New Zealand and Australia, where no parental consent or notification restrictions on under-sixteen access for abortion exist, except in Western Australia where in the event of a girl being under 16 years of age one of her parents must be notified (14-16). Different legislations across the world reflect the ongoing debate about the pros and cons of the necessity for providing parental permission for adolescents' abortion.

\section{Factors in Favor of Mandatory Parental Involvement}

Child welfare strongly depends on the decision whether to have an abortion or continue the pregnancy. The latter would probably have an immense long-term impact on the teen's psychological and 
emotional well-being, her ability to continue formal education, her future financial status, etc. Given that research in developmental psychology in adolescence suggests that adolescents have difficulties in assessing the long-term consequences of their decisions (17), parental involvement can help pregnant teens receive support and guidance from their parents in this important decision. Adolescents who are willing to involve parents in their abortion decision will likely benefit from the adult experience, wisdom, emotional support, and financial support. A comprehensive analysis of the effect of parental involvement (PI) laws on the incidence of abortions to minors in the United States showed that PI laws, enacted before the mid-1990s are associated with a $15 \%$ to $20 \%$ reduction in abortions to minors. However, after this time, the adoption of PI laws had little effect, on average, on abortions to minors (18).

The issues of abuse and coercion should also be taken into account when discussing parental involvement in the adolescent abortion decision. The pregnant adolescent might be pressured into having an abortion by an older or abusive partner in order to conceal the fact that he is guilty of rape or statutory rape. In this case, the involvement of parent(s) is crucial for the support and positive outcome (19).

Since the parents are legally responsible for their adolescent children until the age of majority, some argue that parents have the right to know about any significant activity of their under-aged teens, including their reproductive health care and abortion (20). However, the American Medical Association noted that there is a "remarkable degree of consensus that adolescents should have access to confidential health services and that parental involvement, consent, or notification should not be a barrier to care" which leads us to the other side that advocates against parental involvement parental into the process of adolescent's pregnancy termination (21).

\section{Factors Not in Favor of Mandatory Parental Involvement}

When discussing the competency of adolescents seeking an abortion and the need for parental consent, the very first concern is the age of the adolescent girls. There is a growing body of knowledge regarding adolescent cognitive development related to the decision-making process. The age of 18 years is a convenient legal limit, but there is no specific evidence to support its use as the point at which individuals become competent decision-makers. The existing research shows that the majority of adolescent aged 14 to 17 years are as competent as adults to understand the risks and benefits of abortion, to make voluntary decisions and to provide consent without informing the parents (22-24).

A review on parental involvement laws and parent-daughter communication showed that in countries where parental consent is not obliged, $34 \%$ to $91 \%$ of adolescents told their parents about their pregnancy termination plan (25). Also, in countries where parental involvement is not mandatory, the younger the adolescents, the more likely they were to tell their parents about their intent to have an abortion (25-28). This clearly indicates that the existence of parental involvement laws is not crucial for better communications between adolescents and their parents.

Some parents feel a sense of guilt, thinking that if only they'd done more to protect their child this wouldn't have happened. Parents can put pressure on an adolescent girl, both to give birth and to have an abortion. Mandatory parental notification about the pregnancy and the intent to undergo abortion may be a trigger for family violence which is dangerous for adolescents and may have longterm consequences. A study from the US showed that one-third of adolescents who did not inform their parents had already experienced family violence and fear recurrence (26).

Mandatory parental involvement may lead to the delay of pregnant adolescents' access to timely professional advice and medical care. Delayed or denied abortion has a huge influence on both the emotional health of mothers and the developmental status of children (21). To confirm how important this aspect of delaying abortion is, the American Academy of Pediatrics issued the following statement: "Legislation mandating parental involve- 
ment does not achieve the intended benefit of promoting family communication, but it does increase the risk of harm to the adolescent by delaying access to appropriate medical care. Minors should not be compelled or required to involve their parents in their decisions to obtain abortions, although they should be encouraged to discuss their pregnancies with their parents and other responsible adults" (29).

In favor of those who considered that parental involvement should not be mandatory are the results of a study showing that pregnant adolescents who chose not to communicate with parents were as satisfied with their decisions as those who did consult their parents and received support. Those adolescents who communicated with non-supportive parents were the ones more likely to express dissatisfaction with pregnancy decisions (30). Although no official data are suggesting the associations between parental involvement law and the number of illegal abortions, there is a reasonable concern that parental consent laws have the potential to increase the number of unsafe, illegal, "backalley" abortions.

\section{Conclusion}

Focusing on all previously mentioned arguments, we support the thesis that involving parents in the process of pregnancy termination should not be mandatory. It should be the decision of a competent adolescent and the obligation should rest on the medical professionals to assess the ability of the adolescent to make a competent decision about abortion. Competent adolescents should not be required to involve parents in the decision to get an abortion, in order to protect adolescents who do not have adequate communication with parents and their support. We agree with the position of the American Academy of Pediatrics, which articulated that adolescent should not be forced but encouraged to talk about the choice with trustworthy adults (29). Finally, adolescents should not be left to fend for themselves when it comes to such a difficult decision on abortion, but that they can freely and without fear confide in an adult and competent person, such as a doctor, who can certainly help them. Also, it would be useful to include a psychological counselor in this process, who would help the adolescent to face the dilemma in the right way and make the best decision.

Conflict of Interest: We declare that we have no conflict of interest.

\section{References}

1. World Health Organization. Trends in maternal mortality: 1990 to 2015 - estimates by WHO, UNICEF, UNFPA, World Bank Group and the United Nations Population Division. Geneva: World Health Organization; 2015.

2. Ganchimeg T, Ota E, Morisaki N, Laopaiboon M, Lumbiganon P, Zhang J, et al. Pregnancy and childbirth outcomes among adolescent mothers: a World Health Organization multicountry study. BJOG. 2014;121(Suppl. 1):40-8.

3. Darroch J, Woog V, Bankola A, Ashford L. Adding it up: costs and benefits of meeting the contraceptive needs of adolescents. New York: Guttmacher Institute, 2016.

4. Riley M, Ahmed S, Reed BD, Quint EH. Physician Knowledge and Attitudes around Confidential Care for Minor Patients. J Pediatr Adolesc Gynecol. 2015; 28:234-9.

5. Jaruseviciene L, Lazarus JV, Zaborskis A. Confidentiality and parental involvement in adolescent sexual and reproductive health care: a cross-sectional study of Lithuanian general practitioners. Scand J Public Health. 2011;39(5):484-91.

6. Parental Involvement in Minors' Abortions. Guttmacher Institute. State Laws and Policies. 2020. [cited $2021 \mathrm{Feb}$ 25]. Available: https://www.guttmacher.org/state-policy/ explore/parental-involvement-minors-abortions.

7. Parental Involvement in Minors' Abortions, State Policies in Brief, as of May 25, 2021, Guttmacher Institute. [cited 2021 May 31]. Available from: https://www.guttmacher. $\mathrm{org} /$ state-policy/explore/parental-involvement-minorsabortions.

8. United Nations, Department of Economic and Social Affairs, Population Division (2019). World Population Policies 2017: Abortion laws and policies.

9. Government of Netherland, Abortion. [cited 2021 Feb 25]. Available from: https://www.government.nl/topics/ abortion/question-and-answer/do-i-need-my-parentsconsent-for-an-abortion.

10. Sexual health Switzerland. International Planned Parenthood Federation [IPPF]. European network, abortion legislation in Europe. 2012. [cited 2021 May 31]. Available 
from: https://www.ippfen.org/sites/ippfen/files/2016-12/ Final_Abortion\%20legislation_September2012.pdf.

11. Law on the procedure of termination of pregnancy in healthcare institutions. The Republic of Serbia. Official Gazette of the Republic of Serbia, no 101/2005.

12. Law Library Of Congress, US. Global Legal Research Directorate. Abortion legislation in Europe. Washington, D.C.: Law Library of Congress, Global Legal Research Center, 2015. [cited 2021 Feb 25]. Available from: https:// www.loc.gov/item/2014504237/.

13. BMA 2020. The law and ethics of abortion. [cited 2021 Feb 25]. Available from: https://www.bma.org.uk/me$\mathrm{dia} / 3307 / \mathrm{bma}$-view-on-the-law-and-ethics-of-abortionsept-2020.pdf.

14. Care of Children Act 2004. New Zealand Government. [cited 2021 Feb 25]. Available from: https://www. legislation.govt.nz/act/public/2004/0090/latest/whole. html\#DLM317472.

15. Abortion Law Reform Act 2019 No 11. New South Wales legislation. [cited 2021 Feb 25]. Available from: https:// www.legislation.nsw.gov.au/view/html/inforce/current/ act-2019-011\#statusinformation.

16. Department of Health Western Australia. Working with Youth - A legal resource for community-based health workers. Perth: Department of Health Western Australia; 2007. (Revised 2013.).

17. Steinberg L, Cauffman E. Maturity of judgment in adolescence: Psychosocial factors in adolescent decision-making. Law Hum Behav.. 1996;20(3):249-72.

18. Joyce TJ, Kaestner R, Ward J. The Impact of Parental Involvement Laws on the Abortion Rate of Minors. Demography.2020;57:323-46.

19. Mahkorn S. Pregnancy and Sexual Assault. In Psychological Aspects of Abortion. Mall and Watts (eds). 1979;55-69.

20. Ross OF. Children, families, and healthcare decision making. Oxford: Oxford University Press, 1998.
21. American Medical Association, National Coalition on Adolescent Health. Policy Compendium on Confidential Health Services for Adolescents. Chicago, IL: American Medical Association; 1993.

22. Osuna E. Legal protection of informed consent of minors. Med Law. 2010;29(2):217-26.

23. Steinberg L, Cauffman E, Woolard J, Graham S, Banich M. Are adolescents less mature than adults? Minors' access to abortion, the juvenile death penalty, and the alleged APA “flip-flop”. Am Psychol. 2009;64(7):583-94.

24. Butler A, Bailey D. The maturity and competence of girls obtaining abortions: are parental involvement laws needed? J Policy Pract. 2008;7(1):58-80.

25. Webster RD, Neustadt AN, Whitaker AK, Gilliam ML. Parental involvement laws and parent-daughter communication: policy without proof. Contraception. $2010 ; 82(4): 310-3$.

26. Henshaw SK, Kost K. Parental involvement in minors' abortion decisions. Fam Plann Perspect. 1992;24(5):196207, 213.

27. Ralph L, Gould H, Baker A, Foster DG. The role of parents and partners in minors' decisions to have an abortion and anticipated coping after abortion. J Adolesc Health. 2014;54(4):428-34.

28. Hasselbacher LA, Dekleva A, Tristan S, Gilliam ML. Factors influencing parental involvement among minors seeking an abortion: a qualitative study. Am J Public Health. 2014;104(11):2207-11.

29. Committee On Adolescence. The Adolescent's Right to Confidential Care When Considering Abortion. Pediatrics. 2017;139(2):e20163861.

30. Zabin LS, Hirsch MB, Emerson MR, Raymond E. To whom do inner-city minors talk about their pregnancies? Adolescents' communication with parents and parent surrogates. Fam Plann Perspect. 1992;24(4):148-54. 